\title{
Phytochemical Screening, Total Phenolic Content, Antioxidant and Cytotoxic Activity of Chromolaena laevigata on Human Tumor Cell Lines
}

\author{
Oscar Herrera-Calderon ${ }^{1 *}$, Jorge Luis Arroyo-Acevedo ${ }^{2}$, Juan Rojas-Armas ${ }^{2}$, \\ Victor Chumpitaz-Cerrate ${ }^{3}$, Linder Figueroa-Salvador ${ }^{4}$, Edwin Enciso-Roca ${ }^{5}$ \\ and Johnny Aldo Tinco-Jayo ${ }^{5}$
}

${ }^{1}$ Academic Department of Pharmaceutical Sciences, Faculty of Pharmacy and Biochemistry, Universidad Nacional San Luis Gonzaga de Ica, Ica, Peru. ${ }^{2}$ Laboratory of Experimental Pharmacology, Academic Department of Dynamic Sciences, Faculty of Medicine, Universidad Nacional Mayor de San Marcos, Lima, Peru.

${ }^{3}$ Laboratory of Physiology and Pharmacology, Faculty of Odontology, Universidad Nacional Mayor de San Marcos, Lima, Peru.

${ }^{4}$ School of Medicine, Faculty of Health Sciences, Universidad Peruana de Ciencias Aplicadas, Lima,

${ }^{5}$ Academic Department of Human Medicine, Faculty of Health Sciences, Universidad Nacional San Cristóbal de Huamanga, Ayacucho, Peru.

Authors' contributions

This work was carried out in collaboration between all authors. Authors OHC, JLAA and JRA designed the study, performed the statistical analysis, wrote the protocol and wrote the first draft of the manuscript. Authors VCC and LFS managed the analyses of the study. Authors EER and JATJ managed the literature searches. All authors read and approved the final manuscript.

Article Information

DOI: $10.9734 / A R R B / 2017 / 37045$

Editor(s):

(1) Gunanidhi Dhangadamajhi, Department of Biotechnology, North Orissa University, Baripada, Odisha, India. (2) Md. Torequl Islam, Nuclear of Pharmaceutical Technology (NTF), Postgraduate Program in Pharmaceutical Sciences, Federal University of Piaui, Brazil.

(3) George Perry, Dean and Professor of Biology, University of Texas at San Antonio, USA.

Reviewers:

(1) Divya S. Rajan, Christian College, Kerala University, India. (2) Md. Abu Sayed, Hajee Mohammad Danesh Science and Technology University, Bangladesh. Complete Peer review History: http://www.sciencedomain.org/review-history/22330 


\section{ABSTRACT}

Aims: Cancer is the first cause of death in the Peruvian population; searching alternative treatments of medicinal plants constitute a promissory field to find new anticancer drugs. The main objective in this study was to evaluate the phytochemical screening, total phenolic content, antioxidant and cytotoxic activity of ethanol extract of Chromolaena laevigata ( $C$. laevigata) on human tumor cell lines.

Study Design: The fresh leaves of $C$. laevigata were soaked with ethanol followed by phytochemical screening using standard methods.

Place and Duration of Study: Laboratory of Applied Chemistry, Faculty of Pharmacy and Biochemistry, Universidad Nacional San Luis Gonzaga de Ica, Ica, Peru; Laboratory "Abraham Vaisberg Wolach", Universidad Peruana Cayetano Heredia, Lima, Peru.

Methodology: Phytochemical screening was assessed by using chemical reactives. Total phenolic content (TPC) was developed using Folin Ciocalteu reactive and the antioxidant activity was determined against DPPH and ABTS radicals by spectrophotometry. The cytotoxic activity was determined on human tumor cell lines followed as: MCF-7, H-460, HT-29, M-14, K-562 and DU-145. Results: Phytochemical study confirmed flavonoids and phenolic compounds in ethanol extract. TPC resulted $45.21 \pm 3.5 \mathrm{mg}$ of gallic acid equivalent $/ \mathrm{g}$ of dried extract. The highest antioxidant extract for DPPH and ABTS radical scavenging tests were $I_{50}=11.66 \pm 1.0 \mu \mathrm{g} / \mathrm{mL}, I_{50}=12.45 \pm$ $0.50 \mu \mathrm{g} / \mathrm{mL}$ respectively. Ethanolic extracts $(\mu \mathrm{g} / \mathrm{mL})$ showed a low cytotoxicity on human tumor cell lines $\left(\mathrm{Cl}_{50}>20 \mu \mathrm{g} / \mathrm{mL}\right)$ for DU-145, HT-29, MCF-7 and M-14. Whereas, for $\mathrm{H}-460$, and K562 tumor cell lines showed high cytotoxicity.

Conclusion: In our findings, $C$. laevigata demonstrated a high antioxidant and total phenolic content. The ethanol extract exhibited better cytotoxic effect compared with 5-FU. Hence, This medicinal plant could be effective to prevent chronical diseases as cancer and oxidative stress disorders.

Keywords: Chromolaena laevigata; phytochemical; antioxidant; flavonoids; oxidative stress; cytotoxicity; anticancer.

\section{ABBREVIATIONS}

$\begin{array}{ll}\text { Ch laevigata } & : \text { Chromolaena laevigata; } \\ \text { 5-FU } & \text { :5-Fluoro-uracil; } \\ \text { ABTS } & \text { :2,2'-azino-bis } \\ & \text { (3ethylbenzothiazoline-6-sulfonic } \\ & \text { acid; } \\ \text { DPPH } & : \text { 2,2-diphenyl-1-picrylhydrazyl; } \\ \text { Trolox } & \text { 6-hydroxy-2,5,7,8- } \\ & \text { tetramethylchroman-2-carboxylic } \\ & \text { acid; }\end{array}$

\section{INTRODUCTION}

Cancer is considered as a serious public health problem worldwide that leads to search for antitumor agents, especially from natural sources, which have become an important research field in the scientific community [1]. Cancer is characterized by alteration of gene expressions, cell proliferation, and caused by exposure to carcinogenic agents, mutations and others [2].

Oxidative stress is an imbalance between the production of free radicals and antioxidant system, these generated radicals impairs the essential biomolecules in the cell by oxidizing membrane lipids, enzymes, carbohydrates, cell proteins and DNA [3]. One example is the hydroxyl radical (OH-) which can cause genetic mutation by forming adduct with guanine to form hydroxylated bases of DNA (8 hydroxyl-2'deoxyguanosine) causing transversions of $\mathrm{GC}$ (guanine-cytosine) to TA (thymine-adenine) [4].

Antioxidants are chemical compounds from natural or synthetic sources that can act as chain breakers on radicals such as peroxyl, alkoxyl or hydroxyl, chelating pro-oxidative metal ions and quenching singlet oxygen [5]. New natural products have been studied on many chronical diseases as cancer, diabetes, hypertension and overall those related with oxidative stress process $[6,7]$.

Many medicinal plants are used by patients with cancer due to numerous positive effects on pain relief, vomiting, nauseas, depression, and anxiety [8]. Bioactive compounds such as polyphenols, tannins, flavonoids have antioxidant capacity with potential benefits for health and 
could reduce cancer risk, it has been demonstrated that the anti-inflammatory effect of these compounds inhibit inflammatory cytokines, arachidonic acid (AA), prostaglandins, and leukotrienes [9]. Polyphenols are chemoprotectives that act by blocking the initiation stage of carcinogenesis, free radicals and activation of glutathione peroxidase, glutathione reductase and inactivation of glutathione S transferase [10].

Medicinal plants are the best sources of natural medicine in the world [11]. In Peru, there exists various vegetables species with potential use for commercial purposes and they have been studied by its therapeutic effect for the treatment in various diseases such as cancer, diabetes, and hypertension. Chromolaena laevigata is a species within the family Asteraceae called "chilca". The complementary medicine plays a promising role in cancer symptoms management by facilitating its easy access and administration in-developing countries. These kind of natural supplements are less toxic and provide fewer side effects compared to conventional medications. Therefore, it is important to establish a scientific validation of this species for cancer prevention. Hence, the main objective in this research was to evaluate the preliminary phytochemical screening, total phenolic content, antioxidant and cytotoxic activity of ethanol extract of Chromolaena laevigata on human tumor cell lines.

\section{MATERIALS AND METHODS}

\subsection{Chemicals}

5-Fluorouracil (5-FU), Folin-Ciocalteu reagent (FC), 2,2-diphenyl-1-picrylhydrazyl (DPPH), potassium peroxydisulfate, 2,2'-azino-bis(3ethylbenzothiazoline-6-sulfonic acid) diammonium salt (ABTS), 6-hydroxy-2,5,7,8tetramethylchroman-2-carboxylic acid (trolox), were purchased from Sigma-Aldrich. Other chemicals used were of analytical grade.

\subsection{Plant Material}

Aerial parts of Chromolaena laevigata were collected, in January, 2016, from Chalhuanca, department of Apurimac, Peru, and identified by a botanic. Voucher specimen identified as 272USM-2015 was deposited at the National Herbarium of Universidad Nacional Mayor de San Marcos (UNMSM), Lima, Peru.

\subsection{Extraction of Plant Material}

Collected samples were dried at room temperature, at the Chemical Laboratory, Faculty of Pharmacy and Biochemistry, Universidad Nacional San Luis Gonzaga de Ica (UNICA), the powder material was exhaustively macerated with $96 \%$ ethanol for 7 days. The extract was filtered and evaporated by using a rotavap with $80 \mathrm{rpm}$ and $40^{\circ} \mathrm{C}$.

\subsection{Phytochemical Screening}

Ethanol extract was evaluated by using specific chemical reactives for each secondary metabolite such as phenolic compounds, flavonoids, quinone, triterpenes, flavonoids, tannins, saponins, steroids and alkaloids [12].

\subsection{Total Phenolic Content (TPC)}

The total phenolic content was determined by Folin-Ciocalteu method in according to Singleton and Rossi [13]. Extract was diluted with distilled water. Next, $100 \mu \mathrm{L}$ of the diluted samples, 150 $\mu \mathrm{L}$ of Folin-Ciocalteu's reagent (1/8 diluted in distilled water) and $150 \mu \mathrm{L} 20 \% \quad \mathrm{Na}_{2} \mathrm{CO}_{3}$ were added and mixed. After standing for 5 minutes, $600 \mu \mathrm{L}$ distilled water were added. The absorbance was measured at $760 \mathrm{~nm}$ after 90 min with distilled water as blank sample. Total phenolic content was determined in a standard curve with gallic acid as reference and results were expressed as mg gallic acid equivalents per gram of dried extract.

\subsection{DPPH Radical Scavenging Assay}

In according with the method of Okawa et al., with minor modifications, DPPH radical scavenging activity of extract was determined [14]. To $100 \mu \mathrm{L}$ of different extracts at numerous concentrations ( 1 to $50 \mu \mathrm{g} / \mathrm{mL}$ ) were added to $1900 \mu \mathrm{L} 0.01 \mathrm{mM}$ of DPPH into the test tubes. Next, samples were incubated for $30 \mathrm{~min}$ in a dark place. The absorbances were read by spectrophotometry at $517 \mathrm{~nm}$ using methanol and trolox as blank and standard respectively. The following equation was used to calculate the percent scavenging of the DPPH radical: Antioxidant activity $(\%)=\left[A_{o}-A_{s} / A_{o}\right] \times 100$. Where, $A_{s}$ symbolizes the absorbance of the sample/standard solution and $A_{\circ}$ symbolizes the absorbance of the control. $I_{50}$ value is the concentration of extract at which DPPH radicals 
are scavenged by $50 \%$. The lower $\mathrm{IC}_{50}$ value indicates higher radical scavenging capacity.

\subsection{ABTS Radical Scavenging Assay}

The antioxidant activity was determined on ABTS radical in according to $R e$ et al. [15] Briefly, the reaction mixture $(4.3 \mathrm{mM}$ potassium persulfate and $7 \mathrm{mM}$ ABTS solution) was incubated for $12-$ $16 \mathrm{~h}$ at room temperature, in dark and was diluted, before use, to obtain an absorbance at $734 \mathrm{~nm}$ of $0.7 \pm 0.02$. Next, $40 \mu \mathrm{L}$ of different samples solution were added to $1960 \mu \mathrm{L}$ of reaction mixture and incubated in the dark at room temperature for $7 \mathrm{~min}$; the absorbance was read at $734 \mathrm{~nm}$ using an UV-VIS Spectrophotometer. The ABTS scavenging activity of the extracts was compared with trolox and the percentage inhibition was calculated as:

ABTS radical scavenging activity $(\%)=[($ Abs control - Abs sample) $] /($ Abs control) $\times 100$

Where Abs control is the absorbance of ABTS radical; Abs sample is the absorbance of ABTS radical + extract/standard. ABTS radical scavenging activity of extracts was determined by $\mathrm{IC}_{50}$ value as mentioned above in $\mathrm{DPPH}$ assay.

\subsection{Cytotoxic Activity}

M-14 (human amelanotic melanoma), DU-145 (prostate carcinoma), $\mathrm{H}-460$ (lung large cell carcinoma), HT-29 (colon adenocarcinoma), MCF-7 (breast cancer), and K562 (chronic myelogenous leukemia), 3T3 ((non-tumorogenic, $\mathrm{BALB} / \mathrm{c}$ mouse embryo cells) cell lines were obtained from the American Type Culture Collection (ATCC). The tumor cell lines were cultured in Dulbecco's Modified Eagle Medium (DMEM) supplemented with $10 \%$ fetal calf serum and $50 \mu \mathrm{g} / \mathrm{mL}$ gentamycin in humidified $5 \%$ $\mathrm{CO}_{2} / 95 \%$ air at $37^{\circ} \mathrm{C}$ for $24 \mathrm{~h}$.

In according to Skehan et al. [16] Different dilutions of extract and 5-FU $(0-250 \mu \mathrm{g} / \mathrm{mL})$ were added to different plates containing the human tumor cell lines and incubated for 48 hours. Sulforhodamine B (SRB) was used as dye to determine the cytotoxic activity. Plates were washed with $1 \%$ acetic acid, subsequently a solution $10 \mathrm{mM}$ Tris buffer $(\mathrm{pH} 10.5)$ was added to solubilize the protein-bound dye. The absorbance was read at $510 \mathrm{~nm}$ by using a microplate reader. The results were expressed as half inhibitory concentration $\left(\mathrm{IC}_{50}\right)$ and were found by linear regression analysis.

\subsection{Statistical Analysis}

The antioxidant and cytotoxic activity were expressed as mean \pm standard deviation (SD) from three observations. The statistical and graphical analysis was performed by linear regression in order to determine TPC, antioxidant and cytotoxic activity. Microsoft Excel Program 2016 was used for Rho's Spearman test considering $\mathrm{P}$ values less than 0.05 as significant.

\section{RESULTS AND DISCUSSION}

\subsection{Determination of Phytochemical Constituents}

Phytochemical analysis is a qualitative test which indicates the presence of groups of compounds in a sample by using formation of a precipitate or a color change. The extract of Ch. laevigata indicated various classes of secondary metabolites such as tannins, phenolic compounds and flavonoids; however, quinone was positive in according to Table 1.

Table 1. Phytochemical constituents of the ethanolic extract of Ch. laevigata leaves

\begin{tabular}{lll}
\hline Constituents & Test & Result \\
\hline & Mayer & + \\
Alkaloids & Dragendorff & + \\
& Wagner & + \\
Flavonoid & Shinoda & + \\
Quinone & Bornträger & - \\
Phenols compounds & Ferric chloride & + \\
Saponins & frothing & + \\
Tannins & Gelatin & + \\
Terpenes and steroids & Liebermann-Burchard & + \\
\hline
\end{tabular}




\subsection{Determination of TPC}

Content of total phenolic compounds was detected in the ethanolic extract $(45.21 \pm 3.5 \mathrm{mg}$ $\mathrm{GAE} / \mathrm{g}$ extract). Phenolic content was calculated from the standard curve of gallic acid ( $\mathrm{y}=$ $\left.0.0150 x+0.0435 ; R^{2}=0.991\right)$.

\subsection{Determination of DPPH Radical Scavenging Activity}

The $\mathrm{IC}_{50}$ values against DPPH radical are shown in Fig. $1 \mathrm{~A}$. Compared to trolox the $\mathrm{IC}_{50}$ value of Ch. laevigata was statistically significant $\left(\mathrm{IC}_{50}=\right.$ $11.66 \pm 1.0 ; P<0.001)$.

\subsection{Determination of ABTS Radical Scavenging Activity}

In Fig. 1B, significant differences $(P<0.001)$ were revealed between ABTS scavenging capacities of extract and trolox. Ch. laevigata extract showed a $\mathrm{IC}_{50}$ value $(12.45 \pm 0.50 \mu \mathrm{g} / \mathrm{mL})$ and was not statistically significant $(P=0.211)$ compared to trolox.

\subsection{Cytotoxicity Assay}

Based on the results by linear regression, inhibitory concentration $\left(\mathrm{IC}_{50}\right)$ was calculated and is represented in Table 2. According to the National Cancer Institute (USA), a half inhibitory concentration $\left(\mathrm{IC}_{50}\right)$ less than $20 \mu \mathrm{g} / \mathrm{mL}$ is considered as promising for an extract. The correlation response-concentration was calculated by using Rho's Spearman test, these values were between 0.99 and $-0.98(P<0.001)$ for Ch. laevigata extract and $0.98(P<0.001)$ for $5-\mathrm{FU}$.

\section{DISCUSSION}

The increasing interest for searching natural treatment in cancer disease has led to the evaluation of a number of natural sources. In the present study, Ch. laevigata extract was evaluated in order to determine its potential effect as antioxidant and cytotoxic. To achieve this purpose, the phytochemical analysis, total phenolic content, antioxidant and cytotoxic activity on various tumor cell lines were investigated. The data presented in this study revealed that the ethanol extract presented a good antioxidant activity. This suggests that the extract could protect in vivo systems against oxidative damage and free radical genesis occurring in different pathological mechanisms. The antioxidant activity of plant extracts is usually linked to their phenolic content, furthermore, polar extracts have a high phenolic content due to its high rate of extractions [3]. Preliminary phytochemical analysis is important to confirm the phytochemical characteristics in vegetable species. In this test, the ethanol extract of $\mathrm{Ch}$. laevigata presented phenolic groups, flavonoids, alkaloids, triterpenes and saponins as secondary metabolites; these results were confirmed by Herrera et al. in previous studies [5].

Reactives oxygen species (ROS) and reactives nitrogen species (RNS) play an essential role in the oxidative and nitrosative stress as specified previously. Recently, there has been an upsurge of interest in the therapeutic potential of medicinal plants [17]. The phytochemical products such as phenolic compounds, flavonoids, tannins and terpenoids are responsible for antioxidant effects in vitro and in vivo studies [18]. Furthermore, it is known that flavonoids like rutin and quercetin are antioxidants used to protect the oxidative damage to crucial biomolecules (i.e., DNA, lipids and proteins) involved in numerous diseases [19]. In the scavenging of various free radicals, flavonoids are highly effective by their redox potential. There has been increasing interest in the research on flavonoids obtained from plants since pharmacological properties of flavonoids are directly linked with their antioxidant potentiality [20].

The results in this study endorsed that polyphenolic constituents (i.e., phenolic acids and flavonoids) may be the foremost contributing agents for the antioxidant activity. In this study a high phenolic content was reported for $C h$. laevigata [21]. An earlier study also exposed almost similar findings. Otherwise, this kind of metabolite with phenolic structure has been linked with multiple biological functions in human beings such as anti-inflammatory, anticancer, hypoglycaemic, hypocholesterolemic, antibacterial, antifungal, antiviral activity and analgesic activities [22]. The electron gifting capability of the medicinal plant is most widely determined by DPPH and ABTS radical scavenging tests owing to its reliability. [23] In DPPH assay, purple-colored solution of DPPH radical by accepting electron was converted to discoloured DPPH-H. In fact, the degree of color change is related to the concentration and effectiveness of the antioxidants. The degree of discoloration with respect to decrease in the absorbance of the reaction mixture indicates free 
radical scavenging action [24]. This research suggests that the plant extract that contains flavonoid and related polyphenols are proficient for donating hydrogen to a free radical to prevent the disease related to free radical mediated by oxidative stress [25].

According to the US National Cancer Institute $(\mathrm{NCl})$ to considerer a plant extract as potential cytotoxic agent, $\mathrm{IC}_{50}$ values should be less than $20 \mu \mathrm{g} / \mathrm{mL}$ and for isolated compounds less than $4 \mu \mathrm{g} / \mathrm{mL}$ [26]. The cytotoxic effect of many plant extracts could be related to its antioxidant effect; it has been demonstrated that high doses of antioxidant on tumor cell lines leads to an apoptosis and cytotoxic activity, generally it is attributed to phenolic components, alkaloids, flavonoids, triterpenos and others [27]. However, further molecular mechanistic studies are required to understand the role of these extracts on cytotoxic and apoptotic activity [28]. The cytotoxic effect showed on some tumor cell lines like $\mathrm{H} 460$ and K562 could be linked to one or more phytoconstituents. Cytotoxic agents may cause necrosis; cell membrane destruction leading to cell lysis or induce apoptosis or cell death by activating numerous biochemical mechanisms [29]. The low response of the evaluated extracts to induce cytotoxicity could be explained by its antioxidant effect, it was evidenced that at low concentrations antioxidants have many roles like preventing oxidation, which induces apoptosis. However, at high content can increase the production of ATP (generated by mitochondria) inducing apoptosis in tumor cell lines, via a pro-oxidant mechanism [30].

A

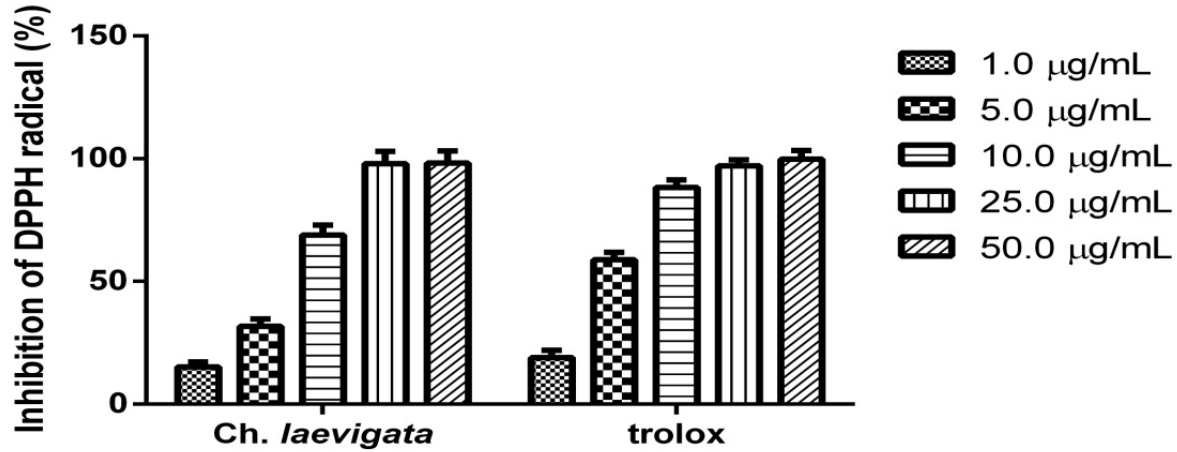

B

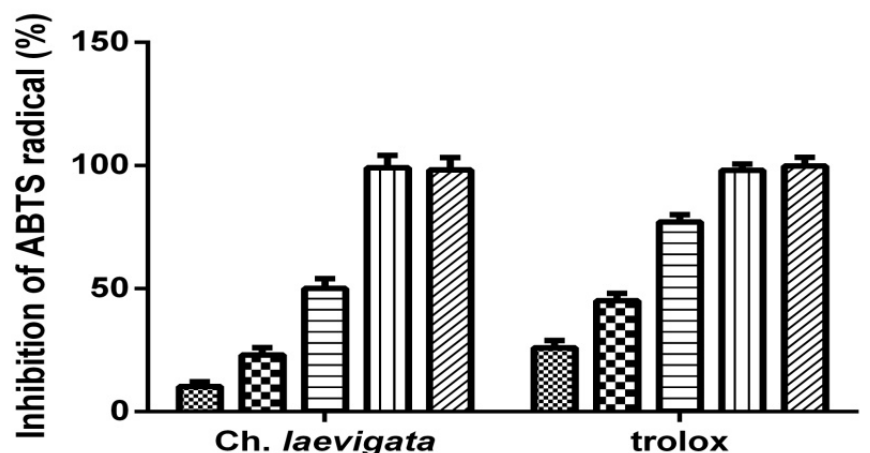

$\$ 881.0 \mu \mathrm{g} / \mathrm{mL}$

$5.0 \mu \mathrm{g} / \mathrm{mL}$

리 $10.0 \mu \mathrm{g} / \mathrm{mL}$

페 $25.0 \mu \mathrm{g} / \mathrm{mL}$

Das $50.0 \mu \mathrm{g} / \mathrm{mL}$

Fig. 1. Antioxidant activity of Ch. laevigata extract and trolox (standard antioxidant) at various concentrations. Values were expressed as mean $\pm S D(n=3)$. A: Percentage of antioxidant activity on DPPH radical. B: Percentage of antioxidant activity on ABTS radical 
Table 2. Cytotoxicity of Ch. laevigata on different human tumor cell lines

\begin{tabular}{|c|c|c|c|c|c|c|c|}
\hline \multirow{3}{*}{$\begin{array}{l}\text { Cytotoxic } \\
\text { samples }\end{array}$} & \multicolumn{6}{|c|}{ Values of $I C_{50}(\mu \mathrm{g} / \mathrm{mL}) \dagger$} & \multirow{3}{*}{$\begin{array}{l}\text { Mouse embryo } \\
\text { normal cells } \\
\text { 3T3 }\end{array}$} \\
\hline & \multicolumn{6}{|c|}{ Tumor cell lines } & \\
\hline & MCF-7 & K-562 & HT-29 & $\mathrm{H}-460$ & M-14 & DU-145 & \\
\hline $\begin{array}{l}\text { Ch. laevigata } \\
\text { 5-FU* }\end{array}$ & $\begin{array}{l}35.25 \pm 0.81 \\
0.645 \pm 0.05\end{array}$ & $\begin{array}{l}7.34 \pm 1.00 \text { * } \\
4.08 \pm 0.54\end{array}$ & $\begin{array}{l}78.52 \pm 2.69 \\
0.33 \pm 0.01\end{array}$ & $\begin{array}{l}55.32 \pm 1.5 \\
0.35 \pm 0.02\end{array}$ & $\begin{array}{l}112.3 \pm 0.60 \\
1.17 \pm 0.09\end{array}$ & $\begin{array}{l}97.09 \pm 0.09 \\
>15.63\end{array}$ & $\begin{array}{l}18.8 \pm 2.10 \\
<0.24\end{array}$ \\
\hline
\end{tabular}


Animals studies are necessary for assessing anticancer properties of medicinal plants, but our findings constitute a first step to discover new alternatives and carry out future assays using in vitro models. On the other hand, isolating phytocompounds could explain the main role of each secondary metabolite in antioxidant and cytotoxic activities of these plants.

\section{CONCLUSION}

In this research, the total phenolic content of five Peruvian plants showed a high content, furthermore, exhibited a strong free radical scavenging activity against DPPH and ABTS radicals. Ch. laevigata extract exhibited cytotoxic activity against $\mathrm{H} 460$ and $\mathrm{K} 562$ cell line, the other extracts presented a low cytotoxicity, however, these plants could be good natural sources of antioxidants and can be applied on alternative treatment for cancer.

\section{COMPETING INTERESTS}

Authors have declared that no competing interests exist.

\section{REFERENCES}

1. Fitzmaurice C, Dicker D, Pain A, Hamavid $\mathrm{H}$, Moradi-Lakeh M, Maclntyre MF, et al. The global burden of cancer 2013. JAMA Oncol. 2015;1:505-2.

2. Van Goietsenoven G, Hutton J, Becker JP, Lallemand B, Robert $F$, Lefranc $F$, et al. Targeting of eEF1A with amaryllidaceae isocarbostyrils as a strategy to combat melanomas. FASEB J. 2010;24:45754584.

3. Arroyo-Acevedo J, Herrera-Calderón O, Chávez-Asmat R, Anampa-Guzmán A, Chumpitaz-Cerrate V, Enciso-Roca E. Protective effect of Chuquiraga spinosa extract on $\mathrm{N}$-methyl-nitrosourea (NMU) induced prostate cancer in rats. Prostate Int. 2017;5(2):47-52.

4. Herrera-Calderon $O$, Santiváñez-Acosta $R$, Pari-Olarte B, Enciso-Roca E, CamposMontes VM, Arroyo-Acevedo JL. Anticonvulsant effect of ethanolic extract of Cyperus articulatus L. leaves on pentylenetetrazol induced seizure in mice. J Tradit Complement Med; 2017.

5. Herrera-Calderon O, Enciso-Roca E, PariOlarte B, Arroyo-Acevedo J. Phytochemical screening, antioxidant activity and analgesic effect of Waltheria ovata Cav. roots in mice. Asian Pac J Trop Dis. 2016;6(12):1000-1003.

6. Rahal A, Kumar A, Singh V, Yadav B, Tiwari R, Chakraborty $S$, et al. Oxidative stress, prooxidants and antioxidants: the interplay. Bio Med Res Int. 2014;1-7.

7. Chambia F, Chirinos R, Pedreschic R, Betalleluz-Pallardel I, Debaste F, Campos D. Antioxidant potential of hydrolyzed polyphenolic extracts from tar (Caesalpinia spinosa) pods. Ind Crops Prod. 2013;47:168-175.

8. Al-Saeedi AH, Hossain MA. Total phenols, total flavonoids contents and free radical scavenging activity of seeds crude extracts of pigeon pea traditionally used in Oman for the treatment of several chronic diseases. Asian Pac J Trop Dis. 2015;5(4):316-321.

9. Casado R, Luanda A, Calvo J, GarciaMina J, Marston A, Hostettmann K, et al. Anti-inflammatory, antioxidant and antifungical activity of Chuquiraga spinosa. Pharm Biol. 2011;49 (6): 620-6.

10. Herrera-Calderon O, Tinco-Jayo JA, Franco-Quino C, Chumpitaz-Cerrate V, Castro-Pari W, Pari-Olarte B, et al. Antioxidant activity and cytotoxic profile of Chuquiraga spinosa Lessing on human tumor cell lines: A promissory plant from Peruvian flora. Asian Pac J Trop Dis. 2017;7(5):304-308

11. Trease E, Evans WC. Trease and evans' pharmacognosy. 15th ed. San Diego: Harcourt Publishers Limited. 2002;343-45.

12. Singleton VL, Rossi JA. Colorimetry of total phenolics with phosphomolybdicphosphotungstic acid reagents. Am J Enol Viticulture. 1965;16:144-58.

13. Okawa M, Kinjo J, Nohara $T$, Ono M. DPPH (1,1-diphenyl-2-picrylhydrazyl) radical scavenging activity of flavonoids obtained from some medicinal plants. Biol Pharm Bull. 2001;24(10):1202-1205.

14. Re R, Pellegrini N, Proteggente A, Pannala A, Yang M, Rice-Evans C. Antioxidant activity applying an improved ABTS radical cation decolorization assay. Free Radic Biol Med. 1999;26:1231-1237.

15. Chang C, Yang $M$, Wen $H$, Chern J. Estimation of total flavonoids content in propolis by two complementary colorimetric methods. J Food Drug Anal. 2002;10:178-82.

16. Hossain MS, Asaduzzaman M, Uddin MS, Noor MAA, Rahman MA, Munira MS. 
Investigation of the in vitro antioxidant and cytotoxic activities of Xanthosoma sagittifolium leaf. Indo Ame J Pharma Res. 2015;5(10):3300.

17. Landa A, Casado R, Calvo MI. Identification of flavonoids from Chuquiraga spinosa, (Asteraceae). Nat Prod Commun. 2009;4(10):1353:5.

18. Bandgar BP, Kinkar SN, Chavan HV, Jalde SS, Shaikh RU, Gacche RN. Synthesis and biological evaluation of asymmetric indole curcumin analogues as potential anti-inflammatory and antioxidant agents. J Enz Inhib Med Chem. 2014;29:7e11.

19. Sawant O, Kadam J, Ghosh R. In vitro free radical scavenging and antioxidant activity of Adiantum lunulactum. J Herb Med Toxicol. 2009;3:39e44.

20. Nijveldt RJ, van Nood E, van Hoorn DEC, Boelens PG, van Norren K, van Leeuwen PAM. Flavonoids: A review of probable mechanisms of action and potential applications. Am J Clin Nutr. 2001;74:41825.

21. Lin HY, Chang ST. Antioxidant potency of phenolic phytochemicals from the root extract of Acacia confusa. Ind Crops Prod. 2013;49:871e878.

22. Huang $D, O u B$, Prior RL. The chemistry behind antioxidant capacity assays. J Agric Food Chem. 2005;53(6):1841-56.

23. Ummuhan SH, Akito N, Iclal S. Antioxidant and cytotoxic effects of Moltkia aurea boiss. Rec Nat Prod. 2012;6:62e66.

24. Kumar S, Sandhir R, Ojha S. Evaluation of antioxidant activity and total phenol in different varieties of Lantana camara leaves. BMC Res Notes. 2014;7:560.
25. Xiao J, Ni X, Kai G, Chen X. A review on structure-activity relationship of dietary polyphenols inhibiting a-amylase. Crit Rev Food Sci Nutr. 2013;53:497e506.

26. Lin HY, Chang ST. Kaempferol glycosides from the twigs of Cinnamomum osmophloeum and their nitric oxide production inhibitory activities. Carbohydr Res. 2012;364:49e53.

27. Wang YH, Avula B, Nanayakkara NPD, Zhao JP, Khan IA. Cassia cinnamon as a source of coumarin in cinnamon-flavored food and food supplements in the United States. J Agric Food Chem. 2013;61: $4470 \mathrm{e} 4476$.

28. Kuete V, Dzotam JK, Voukeng IK, Fankam AG, Efferth T. Cytotoxicity of methanol extracts of Annona muricata, Passiflora edulis and nine other Cameroonian medicinal plants towards multi-factorial drug-resistant cancer cell lines. Springer Plus. 2016;5:1666.

29. Alonso-Carrillo N, de los Ángeles AguilarSantamaría M, Vernon-Carter EJ, Jiménez-Alvarado R, Cruz-Sosa F, Román-Guerrero A. Extraction of phenolic compounds from Satureja macrostema using microwave-ultrasound assisted and reflux methods and evaluation of their antioxidant activity and cytotoxicity. Ind Crops Prod. 2017;103:213-221.

30. González MJ, Rosario-Pérez G, Guzmán AM, Miranda-Massari JR, Duconge J, Lavergne $J$, et al. Mitochondria, energy and cancer: the relationship with trolox. $\mathrm{J}$ Orthomol Med. 2010; 25(1):29-38.

(c) 2017 Herrera-Calderon et al.; This is an Open Access article distributed under the terms of the Creative Commons Attribution License (http://creativecommons.org/licenses/by/4.0), which permits unrestricted use, distribution, and reproduction in any medium, provided the original work is properly cited.

Peer-review history:

The peer review history for this paper can be accessed here: http://sciencedomain.org/review-history/22330 